\title{
THE INTERRELATIONSHIPS AND LINES OF DESCENT OF LIVING INSECTS
}

\author{
By G. C. Crampton, \\ Massachusetts State College, Amherst, Mass.
}

The lines of descent shown in the accompanying phylogenetic tree should be interpreted as though the figure were a three dimensional one (as is indicated by the basal attachments of the branches of the tree), since the usual method of portraying the lines of descent in the form of a dichotomously branching tree, drawn in one plane, does not bring out the fact that several lines of descent may converge upon a common ancestry, and does not indicate the complicated interrelationships of these lines of descent at all accurately. In fact, sections of cones made up of converging lines would better illustrate the fact that some lines of descent intergrade "horizontally" as well as "vertically," but the method of illustrating the interrelationships of the lines of descent shown in the accompanying figure will serve well enough for all practical purposes, if the figure is interpreted as a three dimensional one.

The hypothetical "Protomalacostraca" shown at the base of the phylogenetic tree, represent the extinct common ancestors of the higher Crustacea (such as the Tanaidacea, Mysidacea, Anaspidacea, etc.) insects and "myriopods". The character of the head, with its sessile eyes, the monocondylar mandibles, with their differentiated incisor and projecting molar regions, the large paragnaths, the slender multiarticulate, cerci-like uropods, and other feature of the Tanaidacea (such as Tanais, Apseudes, Leptochelia, etc.) are strikingly suggestive of the precursors of similar structures in the Machiloid insects, and the ancestors of the Tanaidacea (represented by the hypothetical "Prototanaidacea in the diagram) must have been extremely closely related to the more direct ancestors of the Hexapoda (represented in the diagram by the hypothetical "Protohexa- 
poda") and those of the "Myriopoda" (represented in the diagram by the hypothetical "Protosymphyla" — which would include the direct ancestors of the Chilopoda, Pauropoda, etc., as well as those of the Symphyla themselves).

The hypothetical "Protapterygota," or common ancestors of the Apterygota (and consequently the ultimate ancestors of the Pterygota also), are best represented by the Machilislike Apterygota, although some investigators insist that the Dicellura (such as Campodea, Anajapyx, Japyx, etc.), or the Protura, are the most primitive or most "ancestral" insects, despite the fact that the Machilis-like Apterygota are morphologically the most primitive (and hence the most "ancestral") of all insects. Some of the features which indicate that Machilis (or the family Machilidæ), rather than the Dicellura or other forms, represents the ancestral type better than any other living insect, is indicated by the following facts. (1) Machilis has more abdominal limbs (represented by eight pairs of distinct, styli-bearing coxites) than any other insect, including Campodea and other Dicellura. (2) The abdominal limbs, or coxites, of Machilis project free and distinct from the sternites (and the coxites of the ninth segment are hugely developed), while the abdominal limbs of the Dicellura, for example, are reduced to mere styli-bearing areas scarcely distinguishable from the abdominal sternites with which they have merged - and no other Apterygota have more than three pairs of abdominal limbs. (3) The cerci, or limbs of the eleventh abdominal segment, are larger and better developed than those of any other insect. (4) The terminal abdominal segments of Machilis are more distinct, or less fused, than those of the Dicellura, for example. (5) The thoracic terga are better developed and overlap the lateral regions in a more primitive, or Crustaceoid fashion, in Machilis (and Lepisma), while in other Apterygota the thoracic terga are not of this type. (6) The thoracic limbs are best developed in Machilis, and bear styli (epipodites?) in the Machilidae alone. (7) Machilis has primitive compound eyes structurally similar to those of Crustacea, and also has well developed ocelli (which likewise occur in certain trilobites, Anaspidacea, etc.), while the Dicellura are eyeless - as is also the case in the Protura (which likewise lack antennae). (8) Machi- 
lis has preserved the primitive archicephalic or supramandibular suture, characteristic of such Crustacea as Branchippus, Anaspides, etc. (9) The huge flagelliform antennæ of Machilis are the most like those of trilobites and other primitive arthropods. (10) The huge monocondylar mandibles of Machilis are better developed and are more Crustaceoid (with separate incisor and elongated molar regions) than the reduced and highly specialized mandibles of the Dicellura and Protura. (11) The well developed paragnaths (superlinguæ) of Machilis are larger and more Crustaceoid than those of other Apterygota. (12) The well developed maxillæ of Machilis, with their huge limb-like palpi, are far more primitive than those of any other insects. (13) The lacinial fringes of Machilis are more primitively Crustaceoid than those of other insects. (14) The labial palpi etc., of Machilis are better developed, and are of a more primitive character than those of other Apterygotan insects. (15) The traces of the second maxillæ forming the under lip are more distinct in Machilis than in other Apterygota. (16) The head of Machilis is of the ectognathous type, and is much more primitive than the entognathous type (with overgrown mouthparts) found in the Dicellura and Protura, etc.

There are many more features which might be cited to prove that Machilis is more primitive or "ancestral" than any other insect, but the facts cited above should be sufficient to convince any impartial investigator that Machilis is the most ancestral of all insects. Furthermore, its numerous unmistakably Crustaceoid features clearly prove that Machilis, and the other primitive insects descended from similar ancestors, were derived from Crustacea resembling the "Prototanaidacea" in many respects. The well known fact that many Apterygota exhibit striking similarities to various types of "myriopods," merely indicates that both insects and "myriopods" were ultimately descended from the same (Crustacean) ancestry - and the Crustacea are the only intermediate forms serving to connect the insects and "myriopods" with the trilobites and other primitive forms at the base of the common arthropodan stem.

If the Machilidæ are the most primitive or "ancestral" insects, it is obviously misleading to insist that the Dicellura 
(such as Campodea, Anajapyx, etc.) are the most ancestral insects, since they are much more specialized than the Machilidæ. In fact, the Dicellura could readily be derived from a slender blind Nicoletia type of Lepismatid Tysanuroid insect (descended from Machilis like forebears) but by no stretch of the imagination could the primitive Machilis type of insect be derived from any Dicelluran type - which should be the case if the Dicellura represent the ancestral insects (leading back to some type of "myriopod").

Because they have mouthparts of the concealed type, the Dicellura are sometimes grouped with the Collembola (and Protura) in the division Endognatha, in contradistinction to the Ectognatha, or Thysanuroid forms with mouthparts of the exposed type. The modifications of the mouthparts of the Dicellura, however, are not very similar to the modifications exhibited by the Collembola and Protura; and the Dicellura are only very distantly related to the other "endognathous" Apterygota, while the occurrence of cerci, and styli-bearing coxites, in the Dicellura, allies them more closely with the Thysanuroid Apterygota. It is therefore preferable to unite the Dicellura with the Lepismatidæ (Thysanura) and Machilidae (Protothysanura) in the section Styligera, characterized by the occurrence of stylibearing coxites, and cerci, as opposed to the Astyligera (Collembola and Protura), in which these structures are lacking. The Dicellura were possibly derived from some Niceletia-like Lepismatid insect, and the Lepismatidæ themselves were apparently derived from ancestors closely allied to the Machilidæ. The Lepismatidæ, in turn, serve to connect the Machilis-like ancestors of the Apterygota with the ancestors of the Pterygota, which are best represented by "larval" Ephemerida (which have three caudal filaments like those of Thysanuroid Apterygota), so that the Lepismatid line of development is an extremely important one for the study of the evolution of the higher insects.

The Protura are the most primitive representatives of the section Astyligera, although they have lost the eyes and antennæ, and their mouthparts are rather highly specialized. They differ from the rest of insects by the fact that they exhibit a postembryonic increase in the number of segments (they have nine abdominal segments as "larvae", and eleven 
as adults) and are sometimes called Anamerentoma, in contradistinction to the rest of insects (called Holomerentoma) which exhibit no such postembryonic increase in segmentation. Their line of development evidently branched off at the base of the Apterygotan stem, and ends blindly, unless it leads to the Collembola.

The line of development of the Collembola is a rather isolated one, but the Collembola resemble the Protura in that they have a ventral head-groove, a postantennal organ, and similarly modified endognathous mouthparts, etc. The Collembolan line of development may have branched off from that of the Protura, although it is also possible that the Collembola represent degenerate offshoots of the primitive Machiloid ancestors of the Apterygota, since the lacinial fringes of such Collembola as Tetrodontophora are very like those of certain Machilids. In any case, the line of development of the Collembola is a very isolated one, and has no significance for tracing the lines of descent of other insects.

As was mentioned before, the "larvæ" (naiads) of the Ephemerida, with their Lepisma-like terminal filaments (a pair of cerci and an unpaired median terminal filament), and their large paragnaths (superlinguæ), and primitive type of mandibles, provided with a lacinia mobilis like the mandibles of higher Crustacea, etc., are the most archaic representatives of the Pterygota, and suggest that winged insects arose from Lepisma-like forebears, which lead back to the Crustaceoid Apterygota such as Machilis. "Larval" Ephemerida and Odonata agree in having the lacinia and galea united to form a single lobe in the maxilla, and "larval" Ephemerida and Zygoptera agree in having an unpaired median terminal structure, represented by a gill plate in the Zygopteran naiad, and by a terminal filament in the Ephemerid naiad.

The Ephemerida, Odonata, Megasecoptera and Palæodictyoptera, etc., comprise the division of Pterygota called the Palæopterygota, characterized by their inability to lay the wings back along the body in repose. They consequently do not develop a basal fold of the wing, and do not have more than two or three axillary sclerites. Their wings are primitively homonomous, and a neala is not developed in 
them. The rest of the Pterygota comprise the division Neopterygota, characterized by their ability to lay the wings back along the body in repose. They consequently develop a basal fold in the wing, and have more than two or three axillary sclerites. Their wings were originally heteronomous, with an anal fan in the hind wing (though this is lost in many of their descendents), and a neala is developed in the postero-basal region of the wings. This division of the Pterygota is a much more fundamental one than the usual division into Exopterygota and Endopterygota (on the basis of the external or internal development of the wings) which makes an unnatural separation of closely related forms, and lumps together others which are not at all closely related.

The common ancestors of all of these forms are represented in the diagram by the hypothetical "Protopalæodictyoptera". The Palæodictyoptera are the nearest known representatives of these common ancestors, and represent their direct descendents. The Ephemerida were probably derived from the common ancestors of the group by way of the Protephemerida, while the Odonata were derived from them by way of some unknown, extinct forms, to which the Protodonata are very closely related; and the line of descent of the Megasecoptera apparently branched off from the common Palæodictyopteriod stock near the origin of the ancestors of the Odonata. The Odonata are the most "Orthopteroid" of the above-mentioned insects, while the Ephemerida are the most primitive living representatives of the group. The Ephemerida and Protephemerida might be grouped into a superorder called the Panephemeroptera (or Ephemeropteria), characterized by the occurrence of three caudal filaments in many members of the superorder, while the Odonata and Protodonata might be grouped in a second superorder, the Pantyloptera (or Tylopteria) characterized by the skewness of the thorax etc., but too little is known of the morphological details of the fossil forms to enable us to group them correctly at this time.

The Neopterygota may be grouped into three divisions called the Orthopteroid insects (Paurometabola or Orthopteradelphia), the Hemipteroid insects (Parametabola or Hemipteradelphia), and the Neuropteroid insects (Holo- 
metabola or Neuropteradelphia); and the Orthopteroid insects represent the ancestral types of the group as nearly as any known forms. The Orthopteriod insects were apparently not derived directly from the Palæodictyoptera, but were probably derived from the Palæodictyopteran stock by way of Synarmoge (or Synarmogoge as it is sometimes spelled). Since only a fragment of one wing of Synarmogoge is known, however, all that can be said concerning it is that it exhibits certain characters intermediate between the Palæodictyoptera and the Protorthoptera.

The Protorthoptera, shown at the base of the lines of descent of the higher insects in the accompanying phylogenetic tree, include the Protoblattids (which have a demarked claval region in the fore wings) as well as the Protorthoptera in the narrower sense (which have no demarked claval area), since the Protoblattids and Protorthoptera merge so indistinguishably that they may be combined into a single ancestral group from which all of the higher insects were ultimately derived. The Protoblattids are the most primitive representatives of the group, and are more like the direct ancestors of the Blattids, Mantids and Isoptera, while the other members of the Protorthoptera are somewhat closer to the direct ancestors of the Orthoptera.

The Orthopteroid insects are characterized by the fact that the cerci are well developed and the parapodial plates (paraprocts) are distinct in all of the members of the group. An anal fan is developed in the hind wings of most of the Orthopteroid insects, but in some of them, such as the Embiida and Isoptera (excepting Mastotermes) the wings are secondarily homonomous. The Orthopteroid insects have been grouped into three superorders called the Panorthoptera (or Orthopteria), the Panplecoptera (or Plecopteria), and the Panisoptera (or Isopteria).

The superorder Panisoptera (Isopteria) includes the Palæoptera (Blattids and Mantids) and the Isoptera, and is characterized by the fact that the lateral cervical sclerites are contiguous in the midventral line, the mesothoracic trochantins do not unite basally with the episternum; a claval area is usually demarked in the fore wings, and the seventh abdominal sternite projects below the ovipositor in the members of this superorder. The Blattids have pre- 
served the most primitive venation of any living members of the superorder, while the Isoptera have preserved the various features of the body in as primitive a condition as any members of the superorder. These insects are the most primitive of the Orthopteroid insects, and are practically the direct descendents of the Protoblattid type of Protorthoptera.

The Embiids and Plecoptera are included in a superorder called the Panplecoptera (or Plecopteria), characterized by the fact that the postscutellum of the mesothorax is well developed, and the trochantin of the mesothorax unites basally with the episternum above it, in the members of this superorder. The mesothoracic coxæ tend to become ringlike rather than conical, and the tarsi are trimerous. The eighth and ninth abdominal segments are not greatly narrowed in the females of these insects, which are ovipositorless. The Plecoptera are usually grouped with the Odonata and Ephemerida (rather than with the Embiids among the Orthopteroid insects) but the character of their thoracic sclerites is so strikingly similar, and the venation of the fossil forms intergrades so markedly, that there can be no doubt that the Embiids and Plecoptera are extremely closely related, and were descended from a common Protorthopteran ancestry. The fossil Protoperlaria are rather specialized Plecopteroid insects which branched off at the base of the Plecopteran stem, and the fossil Protembiids apparently branched off at the base of the Embiid stem, but the actual Protorthopteran ancestors from which all of these insects were ultimately derived have not as yet been discovered.

The Orthoptera (including the Grylloblattidæ) and the Cheleutoptera, or Phasmida, and possibly the Dermaptera also (although the closest affinities of the Dermaptera may be with the Blattoid insects comprising the superorder Panisoptera), are included in the superorder Panorthoptera (or Orthopteria), characterized by the huge development of the anal fan, and the consequent reduction of the preanal region of the hind wings. The ovipositor is well developed in most of them, and is overlapped basally by the eighth abdominal sternite (excepting the Dermaptera, which may not belong in this superorder). The male genitalia are usually rather symmetrically developed and the cerci fre- 
quently bear mesal prongs, etc., in the members of this superorder.

These insects are the more or less direct descendents of the Protorthoptera in the restricted sense (i.e., the Protorthopteran forms other than the Protoblattids), and their most primitive representatives are the Grylloblattids, which are practically living Protorthoptera, closely related to the Stenopelmatoid Orthoptera (including the Gryllacris-types) . The latter are connected with the Grylloid Orthoptera by the Prophalangopsidæ (and Tridactyloid types), and are connected with the Acridoidea by the Tettigoniidæ (unless the Tridactyloidea furnish the intermediate forms leading to the Acridoidea).

The Hemipteroid or Psocoid insects comprise the division Hemipteradelphia, or Parametabola, characterized by the development of a mesal detached lacinial structure forming a setiform, or a chisel-like portion of the maxilla (excepting the Zoraptera, which have a normal type of maxilla). The insects belonging to this division may be grouped into two superorders, namely the Panpsocoptera (Psocopteria) including the Psocoptera, Mallophaga and Anoplura, and the Panhemiptera (Hemipteria) including the Hemiptera and Thysanoptera. The lacinial structures are usually chisellike in the members of the superorder Panpsocoptera, and are setiform in the members of the superorder Panhemiptera.

The Zoraptera are the most primitive representatives of the Hemipteroid insects, and exhibit so many characters suggestive of a close relationship to the Isoptera, that this might be taken to indicate that they and the Hemipteroid insects in general were derived from the same Protorthopteroid ancestry as the Isoptera were. On the other hand, the venation of the Zoraptera shows that they are members of the order Psocoptera, closely related to such Psocids as Archipsocus and Embidopsocus which exhibit some characters suggestive of a derivation from Embiid-like ancestors; and the Psocoptera in general were probably derived from the common Protorthopteroid ancestors of the Isoptera and Embioptera. The Mallophaga are undoubtedly descended from ancestors extremely closely related to the Psocoptera, and may represent merely degenerate wingless 
Psocoptera. The Anoplura were probably derived from ancestors closely allied to the Mallophaga; and all of these insects are sometimes grouped together as Corrodentia, although they are apparently worthy of ordinal rank.

The mouthparts of the Thysanoptera (which have distinct maxillary and labial palpi) are much more primitive than those of the Hemiptera, and it is possible that the Thysanoptera were descended from a slightly more primitive type than the Hemiptera were. At any rate, the Thysanoptera were apparently descended from Protorthopteroid ancestors very closely related to those from which the Hemiptera were derived, and these ancestors evidently resembled the Psocoptera very closely. The Hemiptera were evidently descended from the same Protorthopteroid ancestors from which the Psocoptera were derived, and the Psocoptera have departed the least of any living insects from the types ancestral to the Hemiptera. Not only does the venation of living Psocoptera parallel that of certain Hemiptera-Homoptera strikingly closely, but the venation of certain fossil Hemiptera merges with that of certain fossil Psocoptera so intimately that there can be no doubt that the two groups had a common Protorthopteroid ancestry; and the fact that many Hemiptera have a claval area demarked in their fore wings may possibly indicate that their Protorthopteroid ancestors resembled Protoblattids (in which the claval area is also demarked) in some respects. At any rate, the Hemiptera could not possibly have been derived from such Palæodictyopteroid insects as Eugereon (mistakenly called "Protohemiptera"), since Eugereon belongs in the section Palæopterygota, whose members are incapable of laying the wings along the body in repose, while the Hemiptera were evidently descended from ancestors capable of laying the wings back along the body in repose, and the venation of primitive Hemiptera does not bear the slightest resemblance to that of Eugereon.

Some Parametabola (Hemipteroid insects) parallel the Holometabola remarkably closely in their method of development, and indicate very clearly that complete metamorposis arose through an increasing divergence between the immature and mature forms (rather than through the precocious emergence of "free-living embryos", as certain 
investigators insist is the case) as the result of mutational changes in the genetic or hereditary material of these insects. Thus in larval Aleurodidæ, for example, the wings arise internally from wing buds, and become external in a quiescent pupal stage, ${ }^{1}$ as they do in the Holometabola; and the development of certain Thysanoptera and other Hemipteroid insects clearly suggests the beginning of Holometabolism.

In this connection, it may be noted that the internal development of the wings in the Aleurodidæ, and the external development of the wings in the closely related Psyllidæ and other Hemiptera-Homoptera, clearly indicates that the usual division of winged insects into Exopterygota and Endopterygota, on the basis of the external or internal development of the wings, is utterly meaningless from the standpoint of phylogeny. Such a division would group together the remotely related Palæodictyopteroid, Orthopteroid and Hemipteroid insects, and would separate the Holometabola from their Orthopteroid relatives, etc.; and this division of winged insects should be abandoned in favor of the more natural and fundamental grouping of winged insects into Palæopterygota and Neopterygota (on the basis of the method of folding the wings in repose), since this grouping does not separate the Holometabola from their Hemipteroid and Orthopteroid relatives.

The section Holometabola (or Neuropteradelphia) includes all insects with complete metamorphosis, and the group is evidently a monophyletic one since their larvæ intergrade so intimately that all of the Holometabola must have had a common ancestry. The fact that some Holometabola are somewhat Psocid-like, and the fact that some Psocoid (or Hemipteroid) insects, such as the Aleurodidæ, etc., clearly foreshadow Holometabolism, would seem to indicate that both Parametabola (Hemipteroids) and Holometabola were descended from closely allied Protorthoptera -which may have resembled the Protoblattids venationally, although their bodies probably exhibited features occurring in the ancestral Isoptera, Embiids and Grylloblattids.

The most primitive representatives of the Holometabola are the Neuroptera, Hymenoptera and Coleoptera, and their

${ }^{1} \mathrm{~A}$ quiescent pupal stage is also foreshadowed in the Isoptera. 
complicated interrelationships (both "vertical" and "horizontal" in the phylogenetic groupings) make it very difficult to decide how to distribute them in the superorders of the Holometabola. There are at least two superorders of Holometabola, in one of which, the Pancoleoptera or Coleopteria (including the Coleoptera and Strepsiptera), the mesothoracic coxae are not divided into eucoxa and meron, the mesothoracic postscutellum is not well developed, and the cerci are usually not developed, while in the other superorder called the Panneuroptera or Neuropteria (including the Neuroptera, Mecoptera, Diptera, Trichoptera, Lepidoptera and Siphonaptera) the mesothoracic coxae are divided into a eucoxa and meron, the mesothoracic postscutellum is usually well developed, and cerci are frequently present.

The Coleoptera are the most Orthopteroid representatives of the Holometabola, and are strikingly similar to the Dermaptera in numerous features of the body. It is possible that the Coleoptera and Dermaptera were derived from Protorthopteroid ancestors which had bodies somewhat like those of the primitive Isoptera, while the wings of their ancestors may have been like those of certain Protoblattid Protorthoptera. At any rate, the wings of the socalled Protocoleoptera (such as Protocoleus) are very Orthopteroid, and may have been derived from a Protorthopteroid type related to the Protoblattids.

The most primitive Coleoptera are the Cantharoid (Lampyroid) beetles, and the Strepsiptera may have been derived from ancestors resembling Cantharoid beetles in some respects. The larvæ of the Strepsiptera are very Meloid in appearance, while the adult Strepsiptera resemble Rhipiphorid beetles in some respects, so that it is very probable that the Strepsiptera were derived from a Coleopteroid stock, although the exact character of their ancestors has not been determined.

The Neuroptera have retained the most primitive type of venation occurring in any Holometabola (with the possible exception of the Mecoptera), and the structures of the body of the primitive Sialid Neuroptera suggest that their ancestors had bodies resembling those of primitive Isoptera and Embiids in many respects, while the venation of the 
Corydalid Neuroptera is rather suggestive of that of certain Protoblattid Protorthoptera. The venation of the Protorthopteroid insect Metropator (which is regarded as a "Palæodictyopteroid" insect by Handlirsch) exhibits certain features suggestive of the precursors of the Sialid type of venation, but Metropator is an oligoneurous form (with few veins) and it is hardly probable that the more richly veined (polyneurous) types of Neuroptera, especially the fossil forms, were derived from the oligoneurous Metropator type of Protorthopteroid insect. In fact, it is very probable that the Protorthopteroid ancestors of the Neuroptera were both oligoneurous and polyneurous, and both tendencies would naturally reappear in their Neuropterous descendents if both tendencies occurred in the ancestral stock. Some investigators consider that the venation of the Neuroptera indicates that they were derived from Palæodictyoptera, but the Neuroptera are clearly Neopterygota capable of laying the wings back along the body in repose, and their larvae intergrade extremely closely with those of the Coleoptera, clearly indicating that the Neuroptera were derived from the same Protorthopteroid ancestors as the Coleoptera, and the venation of the primitive Neuroptera might readily be derived from the type exhibited by certain Protoblattid Protorthoptera.

The Mecoptera are extremely closely related to the Neuroptera, and were evidently derived from the same Protorthopteroid ancestors from which the Neuroptera were descended. The venation of the primitive Mecoptera suggests that their ancestors were similar to the Protoblattid Protorthoptera in certain respects, although Tillyard considers that the Mecoptera were derived from ancestors of the Metropator type, and Tillyard likewise considers that the Mecoptera are more primitive than the Neuroptera. The head and mouthparts of the Mecoptera are more specialized than those of the Sialid Neuroptera, however, and the thoracic sclerites of the Neuroptera are of a much more primitive type than those of the Mecoptera, while some Neuroptera such as Raphidia have retained an Orthopteroid ovipositor which is lost in typical Mecoptera, so that the Neuroptera are more primitive, in general, than the Mecoptera are, and have departed less than the Mecoptera have, 
from the ancestral Holometabolous stock, which was probably a Protorthopteran type with body structures like those of primitive Isoptera and Embiids, and with a venation resembling that of certain Protoblattids. Handlirsch would derive the Mecoptera from Megasecoptera, but the Megasecoptera belong in the section Palæopterygota, whose members are incapable of laying the wings back along the body in repose, while the Mecoptera are clearly Neopterygota capable of laying the wings back along the body in repose, and the resemblance between the venation of certain Mecoptera and Megasecoptera is apparently the result of convergence.

The Diptera were undoubtedly descended from Mecopteralike forebears, as is evidenced by all of their structural features; and fossils such as Aristopsyche (called Paratrichoptera or Protodiptera), which have a venation strikingly suggestive of the ancestors of the Diptera, merge so indistinguishably with the Mecoptera, that it is very doubtful that they are worthy of ordinal rank, and it is preferable to group them with the Mecoptera as a suborder of Mecoptera. Among the living Mecoptera, such forms as Nannochorista have preserved numerous features suggestive of the ancestors of the Diptera, ${ }^{2}$ and clearly indicate that the labella of Diptera, for example, are merely modified segments of the labial palpi.

The Trichoptera have likewise preserved a great number of characters strikingly suggestive of the precursors of the Diptera, but the Trichoptera are more closely allied to the Lepidoptera than any other insects. In fact, the Rhyacophilid Trichoptera merge so indistinguishably with the Micropterygid Lepidoptera that it is very doubtful if the two groups are worthy of ordinal rank, although it is preferable to treat them as distinct orders for the sake of convenience. Fossils such as Belmontia (usually placed in a distinct order the Paramecoptera or Prototrichoptera) are strikingly suggestive of the common ancestors of the Trichoptera and Lepidoptera and lead back to ancestors

2The Tanyderidae and Trichoceridae are the most primitive living Diptera, and the Anisopodidae are very like the ancestors of the Brachycera, whose most primitive representatives are the Therevidae and Rhagionidae (Leptidae), while the Syrphidae have departed but little from the ancestors of the Cyclorrhapha. 
resembling the fossil Mecoptera. The venation of Belmontia is so like that of certain Rhyacophilid Trichoptera that the differences hardly seem to be of ordinal value. At any rate, the Trichoptera have departed the least of any living insects from the ancestors of the Lepidoptera, and the Mecoptera are the nearest living representatives of the forms ancestral to the Trichoptera.

The origin and closest affinities of the Siphonaptera, or fleas, is still a subject of much dispute, and it is impossible to decide the question in the present state of our knowledge of the group. It is quite evident, however, that the Siphonaptera resemble both Diptera and Trichoptera in numerous features of their larval and adult anatomy, and this probably indicates that the fleas were descended from the common ancestors of the Diptera and Trichoptera. Since the Mecoptera are the nearest living representatives of the common ancestors of the Diptera and Trichoptera, the fleas were doubtless derived from Mecopteroid ancestors as yet unknown.

The Hymenoptera combine in themselves so many characters occurring in both the Coleopteroid and the Mecopteroid insects that it is very difficult to determine their closest affinities, although they have a greater number of characters in common with the Mecopteroid insects than with any other group, and their larvae (particularly those of the sawflies) are strikingly similar to larval Mecoptera, Lepidoptera, etc. These facts may be interpreted as indicating that the Hymenoptera should be grouped with the Mecopteroid insects in the superorder Panneuroptera (Neuropteria), but since the Hymenoptera are in many respects intermediate between the Coleopteroid and Mecopteroid insects their annectant character may be better indicated by placing them in a distinct superorder, the Panhymenoptera (or Hymenopteria), occupying a position intermediate between the Mecopteroid insects (Panneuroptera) and Coleopteroid insects (Pancoleoptera), and characterized by the occurrence of an ovipositor (represented by a saw or a sting), forcipate male genitalia, cerci, an Orthopteroid head, etc., and by the absence of the meron in the mesothoracic coxæ.

Tillyard considers that the Hymenoptera were derived 
from the so-called "Protohymenoptera", which have been shown by Carpenter to be merely modified Megasecoptera, having nothing to do with the true ancestors of the Hymenoptera. The Megasecoptera belong in the division Palæopterygota, whose members are incapable of laying the wings back along the body in repose, while the Hymenoptera were evidently descended from ancestors which were capable of laying the wings back along the abdomen in repose. Their ancestors apparently were Protorthoptera with bodies like those of primitive Isoptera and Embiids, while the venation was probably like that of certain Protoblattids. In other words, the Hymenoptera were descended from a common ancestry with the Sialid Neuroptera (and the Lampyroid Coleoptera), and their line of descent also merges with that of the Mecoptera and Trichoptera, or branches off from the common stem near the point of origin of the lines of descent of the Mecopteroid insects. The most primitive living representatives of the Hymenoptera are the Xyelidæ, and the Cephidæ are the nearest representatives of the ancestors of the higher Hymenoptera (or Clistogastra), whose most primitive representatives are the Trigonalidæ.

The views briefly summarized above, have already been presented in a series of papers dealing with the comparative morphology of recent insects in the light of what is known of the fossil forms, but since these views differ very radically from those commonly accepted by recent writers, or by those who have reviewed the recent progress in insect phylogeny, they have not been taken into consideration by recent writers. When a more extensive study of the available evidence is made, however, it becomes readily apparent that many of the currently accepted views are quite untenable; and the foregoing brief summary of certain alternative views on the subject has been made in order to call attention to the fact that the currently accepted views concerning the origin and interrelationships of the insectan orders are not the only possible ones, or necessarily the correct ones, and some consideration should also be given to these alternative views if they are evidently more nearly in accord with the available evidence on the subject. 


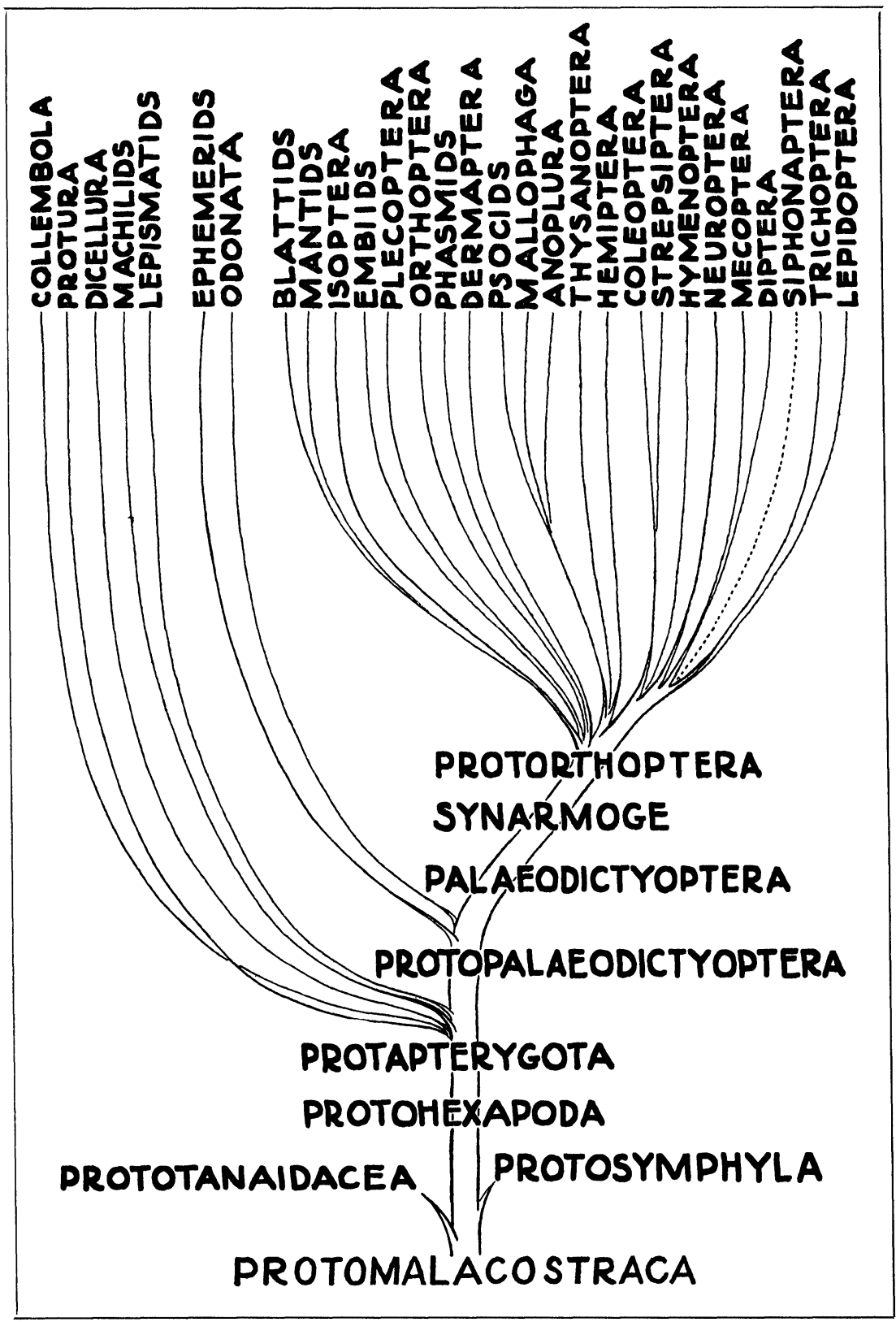

Crampton - Descent of Insects 

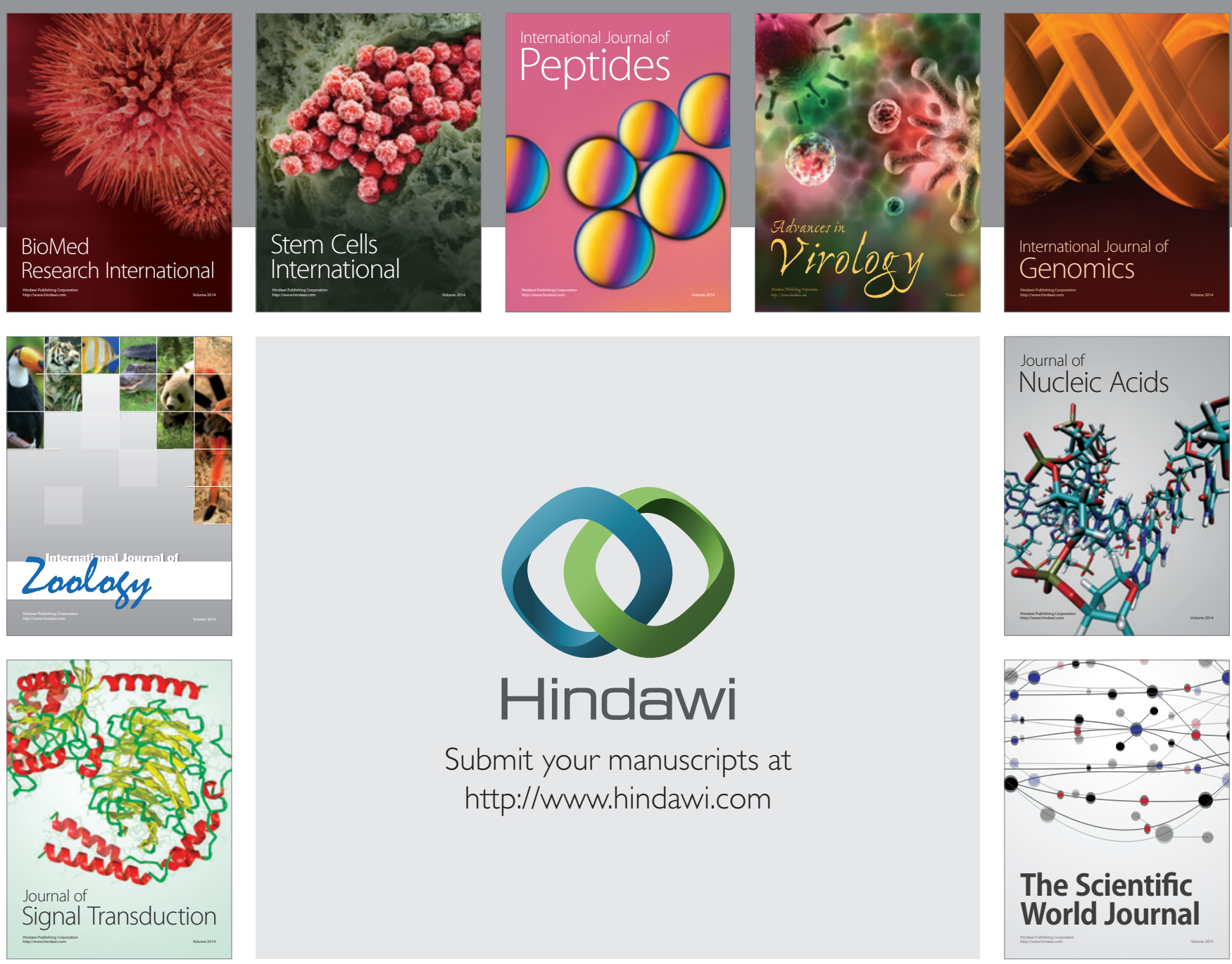

Submit your manuscripts at

http://www.hindawi.com
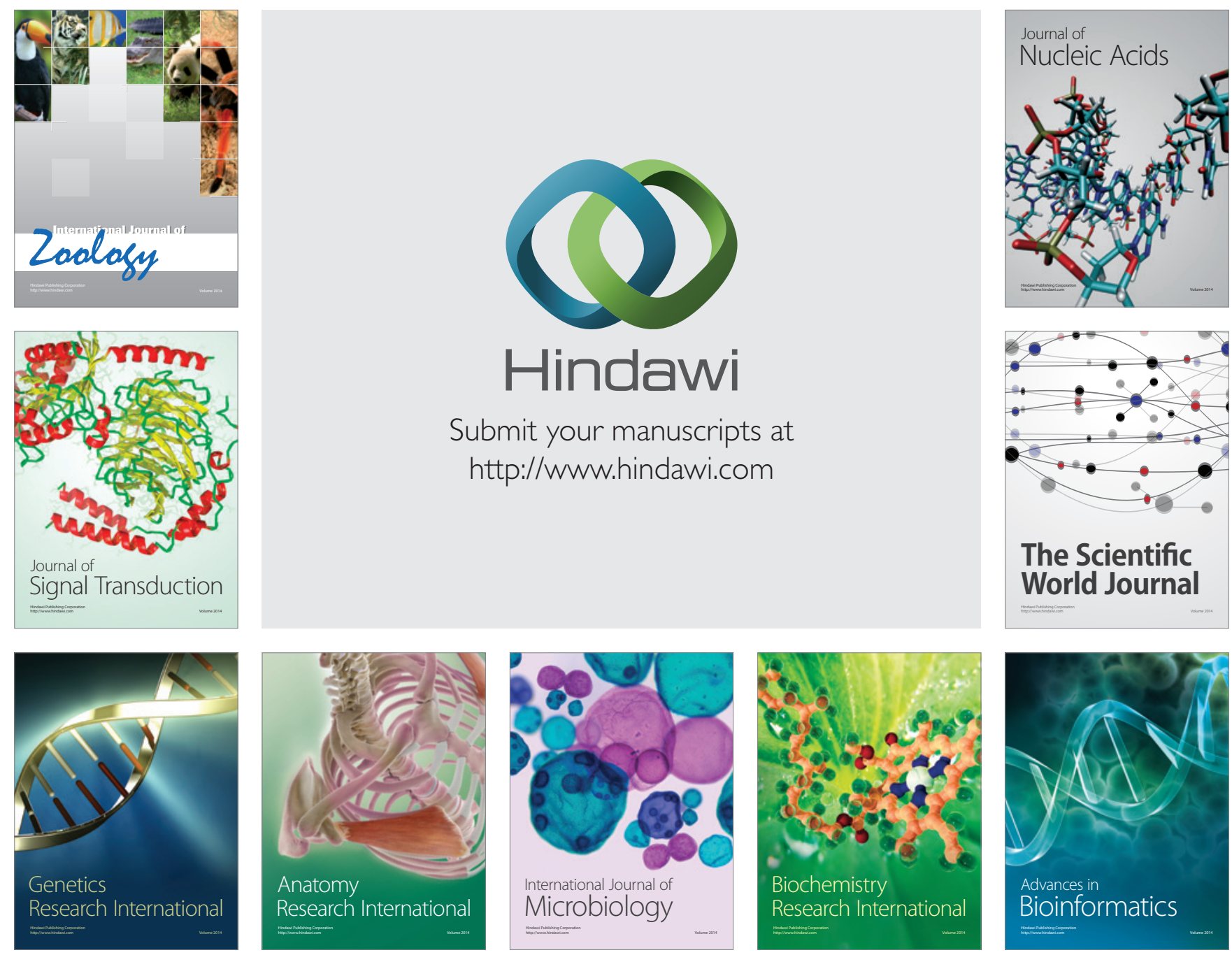

The Scientific World Journal
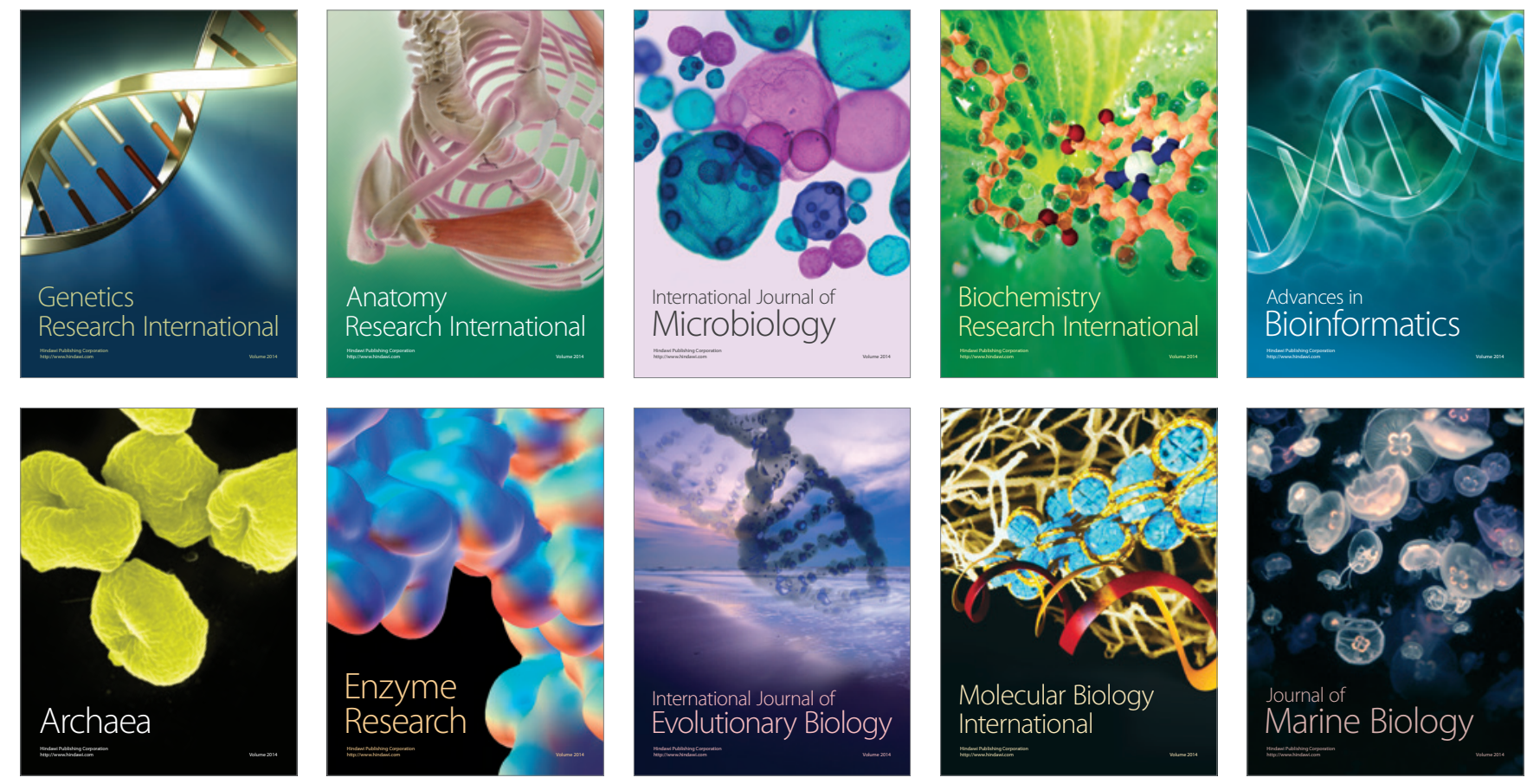